\title{
DÜBLIN
}

Technological University Dublin

ARROW@TU Dublin

Articles

School of Civil and Structural Engineering

2018

\section{Introducing a New Cement Hydration and Microstructure Model}

Niall Holmes

Technological University Dublin, niall.holmes@tudublin.ie

Follow this and additional works at: https://arrow.tudublin.ie/engschcivart

Part of the Structural Engineering Commons

\section{Recommended Citation}

Holmes, J. (2018) Introducing a New Cement Hydration and Microstructure Model Material, Journal of Material Science Engineering . 2018, 7:4 DOI: 10.4172/2169-0022.1000480

This Article is brought to you for free and open access by the School of Civil and Structural Engineering at ARROW@TU Dublin. It has been accepted for inclusion in Articles by an authorized administrator of ARROW@TU Dublin. For more information, please contact arrow.admin@tudublin.ie, aisling.coyne@tudublin.ie, gerard.connolly@tudublin.ie.

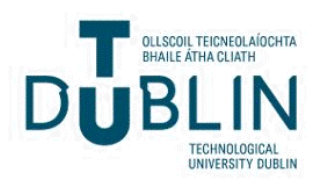




\title{
Journal of Material Sciences \& Engineering
}

\section{Introducing a New Cement Hydration and Microstructure Model}

\section{Niall Holmes*}

School of Civil and Structural Engineering, Dublin Institute of Technology, Dublin 1, Ireland

\begin{abstract}
This paper presents a new cement hydration model (HYDCEM) to predict the microstructure evolution of hydrating tricalcium silicate (C3S). The model is written in MATLAB and employs the continuum approach and integrated particle kinetics relationships to show the change in C3S and the growth of Calcium Silicate Hydrate $(\mathrm{C}-\mathrm{S}-\mathrm{H})$ and Calcium Hydroxide $(\mathrm{CH})$ in the pore space over time.

Cement hydration is a highly complex process. While hydration models should never completely remove experimental analysis, they are an aid to better understand cement hydration and microstructure development by providing a method to analyse a large number of pastes with different cementitious make-ups in a relatively short time. This model uses spherical particles to represent the C3S with customizable input files such as cumulative weight distributions (CWD), to determine the particle size distributions, PSD), w/c ratio, C3S, C-S-H and CH phase densities, kinetics rates, stiochiometries and enthalpy values.

The current study presents simulated microstructures and demonstrates the versatility of the model, while still in the development stage, to simulate cement hydration and microstructure development over 100 days. With further development, it can become a flexible tool for both academia and industry that can easily incorporate the inclusion of supplementary cementitious materials etc.
\end{abstract}

Keywords: Cement; Hydration; Microstructure; Modelling; MATLAB

\section{Introduction}

Cement hydration and microstructure development is a complex process. However, the advances in computing power and range of programmable software in recent years has made the modelling of cement hydration achievable. While computer modelling should never completely replace experimental analysis, it does provide valuable insights into the process particularly with the increased use of supplementary cementitious materials. Model outputs can now be directly compared with experimental analysis provided accurate input data is used throughout.

Cement particles at the micro-scale are made up of four main phases, namely tri-calcium silicate (C3S), di-calcium silicate (C2S), tricalcium aluminate $(\mathrm{C} 3 \mathrm{~A})$ and tetra-calcium aluminate ferrite $(\mathrm{C} 4 \mathrm{AF})$ [1] with a particle size distribution ranging from 40 to $1 \mu \mathrm{m}$. Of the four phases above, C3S is by far the most influential in terms of chemical reactivity and contribution to long term strength gain and makes up approximately $65-70 \%$ of overall cement content. C3S hydration has been the focus of most numerical models due to its influence and relative straightforward reaction and product development. Upon reaction with water, $\mathrm{C} 3 \mathrm{~S}$ produces calcium silicate hydrate (written as $\mathrm{C}-\mathrm{S}-\mathrm{H}$ ) in and around the $\mathrm{C} 3 \mathrm{~S}$ and calcium hydroxide $(\mathrm{CH})$.

A complete and accurate hydration simulation would enable materials engineers not only to predict the performance of concrete in the field, but also to troubleshoot performance problems and even to help design new cementitious materials. Despite significant effort and progress, the ability to perform such a complete simulation has not yet been developed, mainly because cement hydration is one of the more complex phenomena in engineering science.

This paper presents a new model written in MATLAB $^{\circledR}$ to undertake cement hydration and microstructure simulations over any time-period with all input parameters changeable by the user. It aims to overcome of the current limitations with similar vector-based models. Changeable parameters include cumulative weight distributions (CWD), cement properties (including $\mathrm{w} / \mathrm{c}$ ratio, cement phase density and enthalpy) and hydration and microstructure kinetics rates. The model employs the vector approach, which permits a large range of cement phase diameters to be modelled computationally effectively while taking advantage of the inbuilt mathematical functions within MATLAB. The vector approach has been used in several previous hydration models [1-8].

The initial design of the model for the hydration of C3S is presented along with results from a number of simulations using different particle size distributions (PSD).

\section{Current Cement Hydration and Microstructural Models Employing the Vector Approach}

The developments of cement hydration and microstructure models have used either the discretization or the vector approach. Thomas et al. [9] gave a comprehensive review of the most well-known models employing the vector approach and brief overview of these models is presented below.

\section{Jennings and Johnson microstructure simulation model}

This model used spherical particles within a cubic volume with the reducing diameter of $\mathrm{C} 3 \mathrm{~S}$ and increasing inner and outer $\mathrm{C}-\mathrm{S}-\mathrm{H}$ predicted as hydration continued over time [5]. The model also determined the number of new $\mathrm{CH}$ particles and placed them in the pore space. The overlapping of particles, and how the hydration and microstructure is affected, was also simulated. Due to the limited

${ }^{*}$ Corresponding author: Holmes N, School of Civil and Structural Engineering Dublin Institute of Technology, Dublin 1, Ireland, Tel: +353 1402 4039; E-mail: niall.holmes@dit.ie

Received July 22, 2018; Accepted August 27, 2018; Published September 07, 2018

Citation: Holmes N (2018) Introducing a New Cement Hydration and Microstructure Model. J Material Sci Eng 7: 480. doi: 10.4172/2169-0022.1000480

Copyright: ( 2018 Holmes N. This is an open-access article distributed under the terms of the Creative Commons Attribution License, which permits unrestricted use, distribution, and reproduction in any medium, provided the original author and source are credited. 
computational power at the time, the model was not developed further but it did provide a methodology for future programmes using this approach. Figure 1 shows an image from their model, which consists of $1,000 \mathrm{C} 3 \mathrm{~S}$ and $1,000 \mathrm{CH}$ crystals after $50 \%$ hydration.

\section{Navi and Pignat model}

In 1990s, the integrated particle kinetics model was developed by Navi and Pignat $[3,6-8]$. This model simulated the hydration of spherical C3S particles using a similar vector approach as the Jennings and Johnson model [5]. This model used kinetics laws and relationships that simulated every particle. Hydration was simulated in three phases. Initially an Avrami-type equation was used, followed by a phase-boundary analysis which depended on the particles surface area and finally a diffusion-type where the rate of C3S consumption was inversely proportional to the thickness of hydrates deposited on the surface of cement particles. This approach was found to be very computationally expensive and as a result, the number of particles had to be limited to $\sim 10,000$. An example of their models output is shown in Figure 2.

\section{HYMOSTRUC model}

The hydration, morphology, and structural (HYMOSTRUC) model was developed by van Breugel [2] and simulates the 3D hydration of spherical particles. Reacting particles form concentric hydrating layers around the original cement grains, which grow and intersect with each

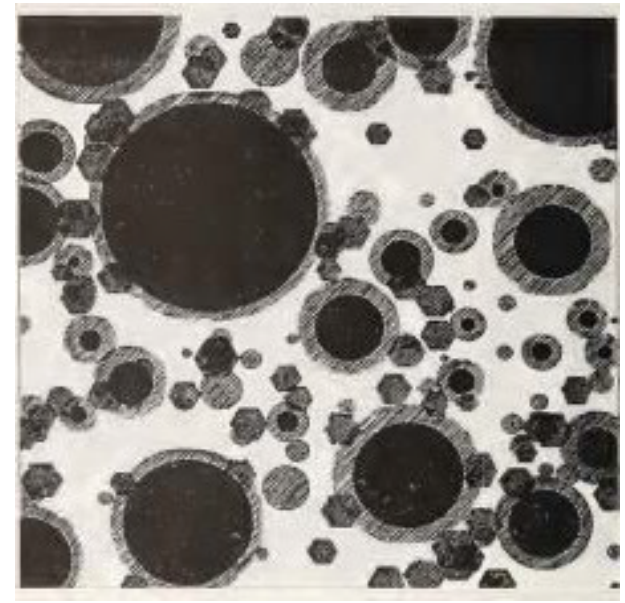

Figure 1: 2D image from the Jennings and Johnston model at $50 \%$ hydration [5].
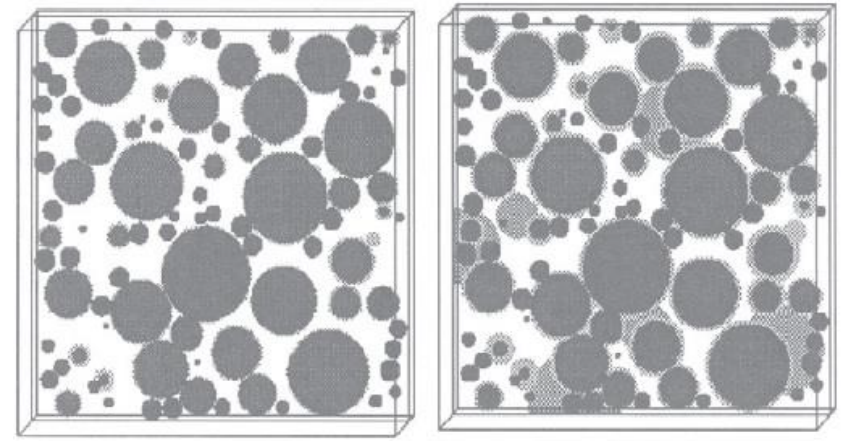

Figure 2: Output at 6-hours (left) and 1-day (right) [3,6-8] other (Figure 3). It employs various mass and volume balance rules to accommodate microstructural changes from the dissolution and precipitation of various phases. HYMOSTRUC, however, does not accurately predict the evolution of the cement microstructure nor does it account for the changing chemistry or transport properties. Recent developments include for random packing of particles and the calculation of autogenous shrinkage. Also, not every individual particle is allowed to hydrate as the authors feel the computation time would be too large. Therefore, a statistical approach to reaction rates is used that assumes the reaction rate of each particle depends only on its size. As the particle interactions or overlaps are not analysed, the microstructure information is not available.

\section{The HydratiCA simulation model}

The HydratiCA model has been developed by Bullard at NIST [10] and is based on more fundamental principles of hydration kinetics. HydratiCA directly simulates the (1) dissolution and growth of mineral phases, (2) diffusion of mobile species in solution, (3) complexation reactions among species in solution or at solid surfaces and (4) nucleation of new phases (Figure 4). The principles of detailed balances and mass action are used to unify these disparate kinetics processes.

HydratiCA makes more detailed predictions of the kinetics of phase changes and microstructure development as a function of solution chemistry and temperature than other microstructure-based models of hydration. However, it is very computationally intensive with simulations requiring small time steps of about 0.2 milliseconds to ensure numerical stability. As a result, approximately 18 million steps are required to simulate just 1 hour of hydration. HydratiCA has been used to investigate various mechanisms of hydration of $\mathrm{C} 3 \mathrm{~S}$ and tricalcium aluminate $(\mathrm{C} 3 \mathrm{~A})$.

\section{The $\mu$ ic microstructure model}

The $\mu$ ic (pronounced "mike") microstructural modelling platform [11] is a continuation of the work done by Navi and Pignat $[3,6-8]$, which was, in turn, based on the original Jennings and Johnson model [5] discussed above. $\mu$ ic has been written using object-oriented programming in Java and simulates the growth of spherical particles to mimic hydration. As such, it makes significant advances on the limitations of previous methods due to inadequate computational

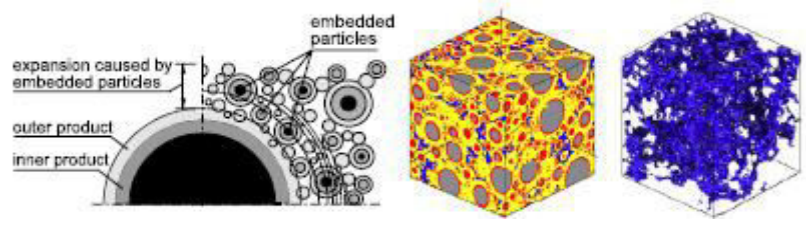

Figure 3: Typical HYMOSTRUC hydration simulations [2].

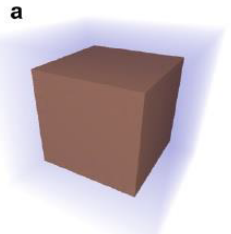

b

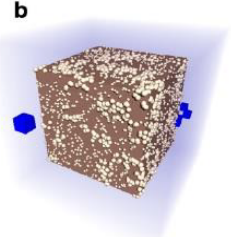

c

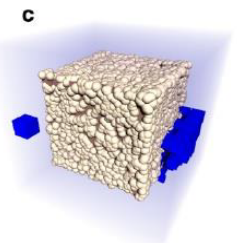

Figure 4: HydratiCA simulation of a single cubic particle of C3S at (a) start of HydratiCA simulation, (b) $3.5 \mathrm{~h}$ of hydration, corresponding to maximum hydration rate and (c) $24 \mathrm{~h}$ of hydration [10]. 
power at the time. The support libraries within $\mu$ ic allow for the hydration modelling of millions of cement particles (Figure 5), which more realistically represent real PSD's.

The main advantage of $\mu$ ic is the fully customizable nature of the simulations by the user including the initial PSD, defining the phases and their composition and the stoichiometry of the reactions to be simulated. While the large number of customizable elements to be set up can be tedious, its flexibility makes $\mu$ ic a valuable hydration study tool.

\section{CEMHYD3D Hydration Model}

While not specifically employing the vector approach, no review of cement hydration models is complete without including the CEMHYD3D model [12]. CEMHYD3D is one of the most widely used and well known hydration and microstructure models and employs the discrete or pixel approach and the cellular-automata (CA) method. The microstructure is presented as a grid of discrete three-dimensional cubic elements (Figure 5), called volume-pixels, each representing an anhydrous or hydrate phase or pore.

In CEMHYD3D, CA is used to simulate the diffusion of species through the pore-water leading to reactions and precipitations, which either dissolves or reacts and forms a product of hydration. However, due to the maximum pixel size of $1 \mu \mathrm{m}$, particles below that are not included.

\section{Summary}

Up until $\mu$ ic, the computation ability of hydration models was restricted with limitations on the number $(>10,000)$ and size $(<1 \mu \mathrm{m})$ of particles possible. However, with the ever increasing processing power and online support libraries and forums with modern programming languages, these issues can now be easily overcome. Another important requirement of a hydration model is how it can be easily customised for the user in terms of input parameters and reducing 'hard-wired' or built-in physical or chemical properties while not compromising performance or critical cement hydration and microstructure processes.

The new model presented here is based on the combined work of Navi and Pignat [3,6-8] and Bishnoi [11] and is focussed on the hydration of C3S particles using the vector approach for any diameter and number. The model calculates and simulates the growth of $\mathrm{C}-\mathrm{S}-\mathrm{H}$ between the original and reducing C3S grain and around the particle as its expands into the pore space. The computations here will be undertaken in MATLAB which is well suited to the extensive calculations employed in cement hydration modelling due its use of vector and matrix input and storage of data. The readability of both the input and output make checking the results simple (Figure 6).

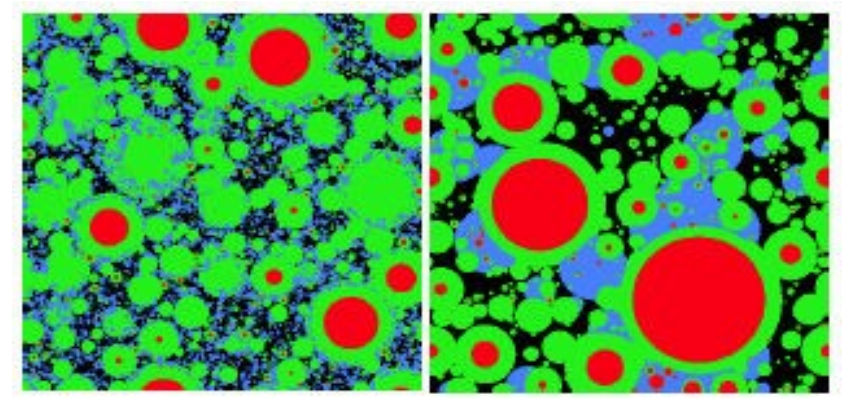

Figure 5: Typical $\mu$ ic microstructure simulations [11]

\section{Model Design}

The model was created to employ the problem solving speed of MATLAB utilising the full suite of inbuilt functions and the inherent stability of the programme to set-up and simulate the hydration of tens of thousands of cement particles within a $100 \mu \mathrm{m}$ volume. The model is also setup to be as user friendly as possible with key properties changeable before starting hydration. Unlike $\mu$ ic, this model is designed to undertake the analysis with minimal user input values. Two *.txt files are loaded into the programme which are described in detail below. Many different formats are possible to input for MATLAB with ${ }^{\star}$.txt chosen as a personal preference. Furthermore, MATLAB is a reasonably easy language to learn and apply as it's based on matrix mathematics. The use of comments throughout improve the readability of the code. Figure 7 presents a flow diagram of how the model performs the analysis and highlights the customisability of it for the user.

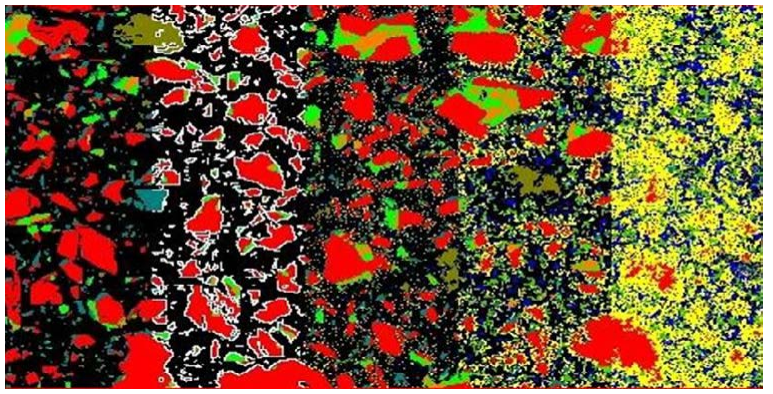

Figure 6: Sample output from CEMHYD3D model [12]

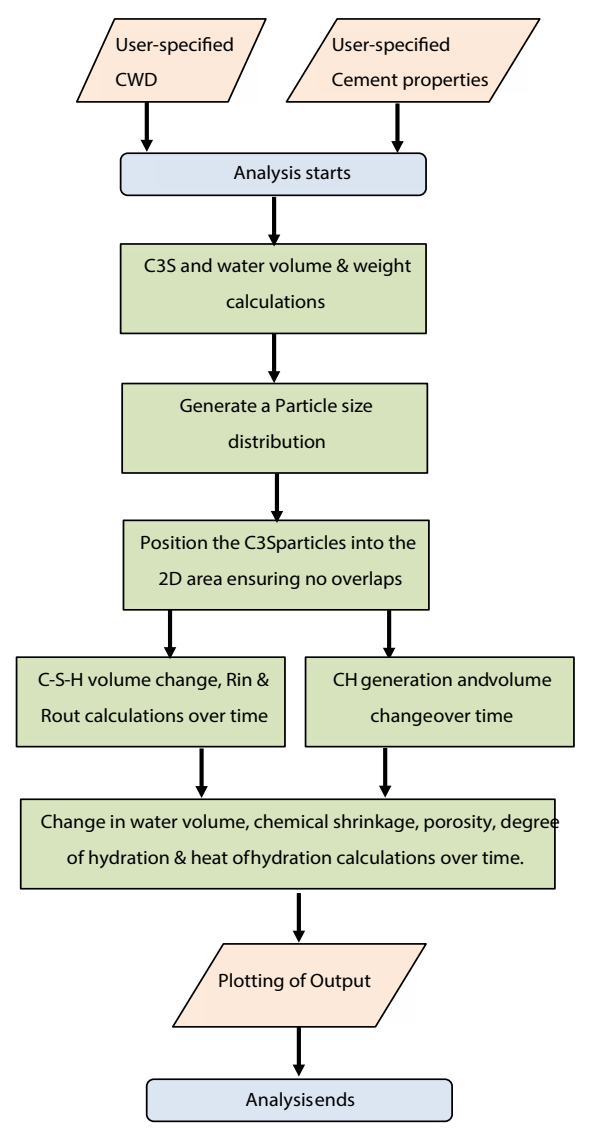

Figure 7: HYDCEM analysis flow diagram. 


\section{User customisable input}

As mentioned above, users have flexibility on input via two *.txt files. The first describes the CWD, which the model uses to determine the PSD and number of particles. The CWD input is read into the model via two row vectors with no limit on the number of input columns. The second input file allows the user to customise the cement properties including $\mathrm{w} / \mathrm{c}$ ratio, volume size, $\mathrm{C} 3 \mathrm{~S}$ and $\mathrm{CH}$ density $\left(\mathrm{g} / \mathrm{cm}^{3}\right)$, time step size (hours) and duration of analysis (days). This file also contains hydration kinetics, reaction stoichiometry, $\mathrm{CH}$ growth constants and C3S enthalpy values. Examples of the input data will be discussed in more detail in the next section by means of a worked example.

\section{Materials}

The model, using user defined kinetics and stoichiometries, will output the volume of reaction products from the original C3S particles, namely C-S-H and $\mathrm{CH}$. Each material has its density, reaction stoichiometry defined. For instance, what proportion of C-S-H should be defined as inner C-S-H and outer C-S-H and subsequently deposited on the C3S particle with their particular density defined and volume determined. Four types of materials are defined and simulated (Figure 8).

\section{Reactions}

The reactions are defined in the model using the input parameters described above. The volumes, using the different stoichiometries and densities, are calculated. The reducing water volume is also calculated and is related to the continued reactivity of the C3S particles. Eqn. (1) shows the governing hydration of $\mathrm{C} 3 \mathrm{~S}$ upon reaction with 5.3 moles of water $(\mathrm{H})$ which produces $\mathrm{C}-\mathrm{S}-\mathrm{H}$ and 1.3 moles of $\mathrm{CH}$. Eqn. (2) shows the volumetric ratios of $\mathrm{C} 3 \mathrm{~S}$ hydration, where each volume unit of $\mathrm{C} 3 \mathrm{~S}$ reacts with 1.318 volume units of water to produce 1.57 volume units of C-S- $\mathrm{H}$ and 0.593 volume units of $\mathrm{CH}$. The densities of $\mathrm{C} 3 \mathrm{~S}, \mathrm{H}_{2} \mathrm{O}$ and $\mathrm{CH}$ are taken as $3.15 \mathrm{~g} / \mathrm{cm}^{3}, 1.0 \mathrm{~g} / \mathrm{ml}$ and $2.24 \mathrm{~g} / \mathrm{cm}^{3}$ respectively.

$$
\begin{aligned}
& \mathrm{C} 3 \mathrm{~S}+5.3 \mathrm{H} \rightarrow \mathrm{C}_{1.7} \mathrm{SH}_{4}+1.3 \mathrm{CH} \\
& 1.0 \mathrm{~V}_{\mathrm{C} 3 \mathrm{~S}}+1.318 \mathrm{~V}_{\mathrm{H} 2 \mathrm{O}} \rightarrow 1.57 \mathrm{~V}_{\mathrm{C}-\mathrm{S}-\mathrm{H}}+0.593 \mathrm{~V}_{\mathrm{CH}}
\end{aligned}
$$

\section{Worked Examples}

The following section describes examples of analysis undertaken on C3S particles with different CWD based on rules for hydration described by Pignat et al. [3,6-8] including hydration and microstructure kinetics rates are fully customisable in the model by the user before the analysis begins. The results demonstrate the ease of use of the model and speed of calculations. The following sections provide an overview of the steps undertaken during the analysis with input and output shown in figures and tables.

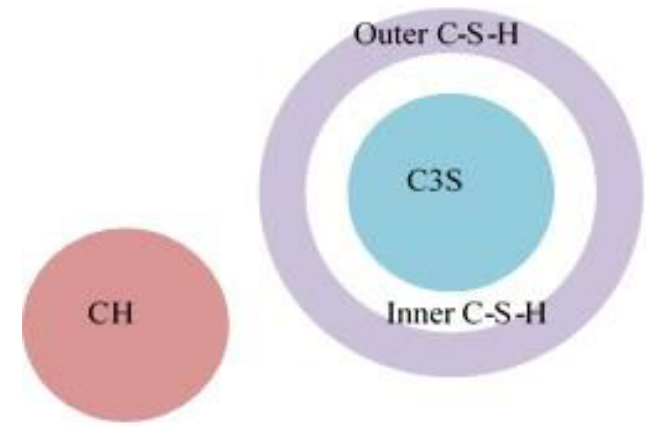

Figure 8: Different materials and particle types defined in a simulation (after Bishnoi, [11]).

\section{Particle size distribution}

To determine the PSD, the CWD is loaded into the model via a ${ }^{*}$.txt file. The CWD's shown in Table 1 were developed by the author (bar cement C1, [8]) for a $0.4 \mathrm{w} / \mathrm{c}$ cement within a $100 \times 100 \times 100 \mu \mathrm{m}$ volume. The four CWD's (Figure 9) produces 2,628, 17,128, 55,449 and 96,579 C3S particles (Figure 10). Using the w/c ratio, the length of each side (100 $\mu \mathrm{m}$ typically) and density of cement and water (3.15 and 1.0 $\mathrm{g} / \mathrm{cm}^{3}$ respectively), the model calculates the volume fraction, volume and weight of cement and water.

The model places the largest diameter particle $(40.4 \mu \mathrm{m}$ in this instance) first and determines the volume remaining, the volume fraction remaining and, from the original CWD, and so on until no volume is remaining. The model then places each particle within the volume ensuring there are no overlaps.

\section{Hydration and microstructure calculations}

The input data for the second ${ }^{*}$.txt file is shown in Table 2 . The value for the density of $\mathrm{C} 3 \mathrm{~S}$ varies amongst researchers so the value

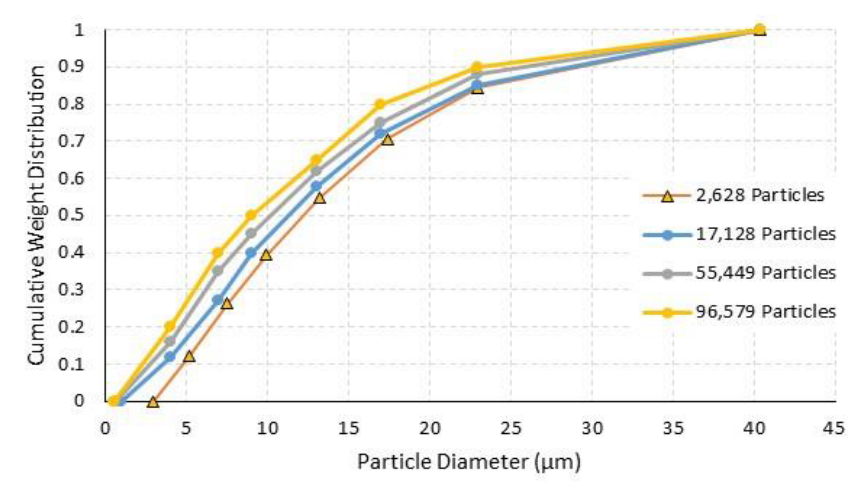

Figure 9: Particle size distributions used in this analysis.

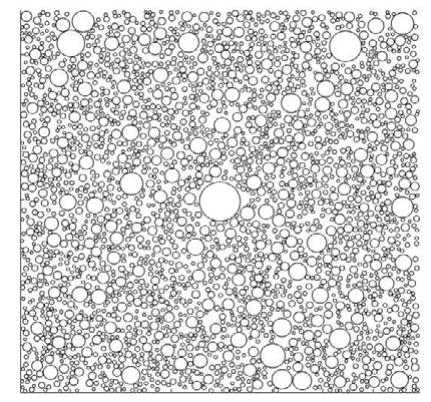

(a) 2,628 particles

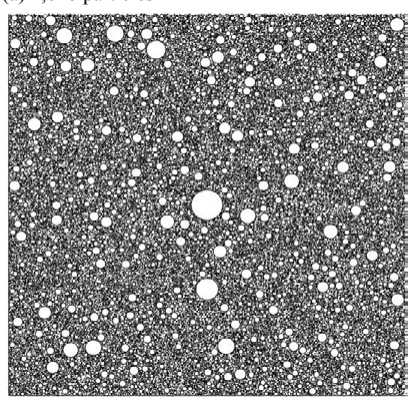

(c) 55,149 particles

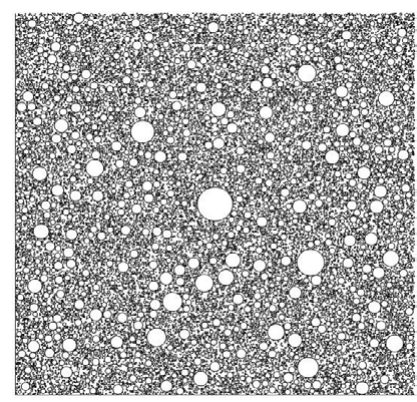
(b) 17,128 particles

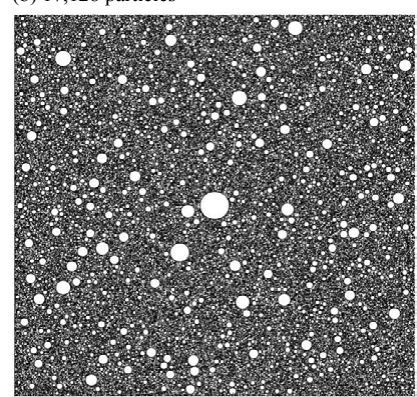

(d) 96,579 particles

Figure 10: 2D particle distributions for cements $C_{1-4}$ 
Page 5 of 10

\begin{tabular}{|c|c|c|c|c|c|c|c|}
\hline $\begin{array}{l}\text { Particle diameter } \\
\qquad(\mu \mathrm{m})\end{array}$ & CWD & Particle diameter $(\mu \mathrm{m})$ & CWD & Particle diameter $(\mu \mathrm{m})$ & CWD & $\begin{array}{l}\text { Particle diameter } \\
\qquad(\mu \mathrm{m})\end{array}$ & CWD \\
\hline \multicolumn{2}{|c|}{ Cement 1} & \multicolumn{2}{|c|}{ Cement 2} & \multicolumn{2}{|c|}{ Cement 3} & \multicolumn{2}{|c|}{ Cement 4} \\
\hline 40.4 & 1 & 40.4 & 1 & 40.4 & 1 & 40.4 & 1 \\
\hline 23 & 0.845 & 23.0 & 0.85 & 23.0 & 0.88 & 23.0 & 0.90 \\
\hline 17.4 & 0.706 & 17.0 & 0.72 & 17.0 & 0.75 & 17.0 & 0.80 \\
\hline 13.2 & 0.547 & 13.0 & 0.58 & 13.0 & 0.62 & 13.0 & 0.65 \\
\hline 9.94 & 0.395 & 9.0 & 0.4 & 9.0 & 0.45 & 9.0 & 0.50 \\
\hline 7.51 & 0.263 & 7.0 & 0.27 & 7.0 & 0.35 & 7.0 & 0.40 \\
\hline 5.17 & 0.123 & 4.0 & 0.12 & 4.0 & 0.16 & 4.0 & 0.20 \\
\hline 2.95 & 0 & 1.0 & 0 & 0.6 & 0 & 0.5 & 0 \\
\hline \multicolumn{2}{|c|}{ \#particles=2,628 } & \multicolumn{2}{|c|}{ \#particles=17,128 } & \multicolumn{2}{|c|}{ \#particles $=55,449$} & \multicolumn{2}{|c|}{ \#particles=96,579 } \\
\hline
\end{tabular}

Table 1: Particle diameter $(\mu \mathrm{m})$ and CWD

\begin{tabular}{|l|c|}
\hline Property & Input \\
\hline w/c ratio & 0.4 \\
\hline Box size $(\mu \mathrm{m})$ & 100 \\
\hline C3S phase density $\left(\mathrm{g} / \mathrm{cm}^{3}\right)$ & 3.15 \\
\hline Duration of hydration $($ days) & 100 \\
\hline Hydration rate $(\mathrm{K} 1, \mu \mathrm{m} / \mathrm{hr})$ & 0.012 \\
\hline Hydration rate $\left(\mathrm{K} 2, \mu \mathrm{m}^{2} / \mathrm{hr}\right)$ & 0.006 \\
\hline rout - rin $(\mu \mathrm{m})$ & 4 \\
\hline Volume of C3S converted to inner C-S-H & 1.00 \\
\hline Volume of C3S converted to outer C-S-H & 0.57 \\
\hline CH constant 1 & 0.2 \\
\hline CH constant 2 & 0.213 \\
\hline Volume of C3S converted to CH & 0.593 \\
\hline CH phase density (g/cm $\left.{ }^{3}\right)$ & 2.24 \\
\hline Volume water used during C3S reactions & 1.318 \\
\hline C3S enthalpy $(\mathrm{J} / \mathrm{g})$ & 500 \\
\hline Hydration plot 1 (days) & 0 \\
\hline Hydration plot 1 (days) & 7 \\
\hline Hydration plot 1 (days) & 28 \\
\hline Hydration plot 1 (days) & 91 \\
\hline
\end{tabular}

Table 2: Cement properties input into the model.

used $\left(3.15 \mathrm{~g} / \mathrm{cm}^{3}\right)$ is based on the published value given by [11]. A time step of 1-hour was chosen for the analysis for 100 days, giving 2400 steps in total.

\section{Particle kinetics}

The hydration of cement has been described by previous modellers $[3,6-8,11]$ as three mechanisms over different time scales. The first is nucleation and growth which is the subject of much discussion amongst researchers in this area. There is widespread disagreement between the precise cause of very rapid heat production and reduction within the initial 1-2 hours. Some believe this is due to the formation of a meta-stable layer of hydrates around the reacting particles $[13,14]$. Others [15] believe it is based on a geochemical approach where, during cement hydration, dissolution is initially dominated by the formation of etch pits on surfaces and later becomes limited to step retreat from such.

As this period of hydration is quite short (1-2 hours) and contributes little to the final strength, it has been left out of the analysis here. The second mechanism is commonly referred to as 'the phase boundary controlled reaction' [11]. Here, the hydration productions of C-S-H inner and outer are formed around the C3S particle and $\mathrm{CH}$ is formed in the pore space. The growth of the thickness of the inner product is given by eqn. (3) $[3,6-8,11]$ where $\mathrm{K} 1$ is in units of $\mu \mathrm{m} / \mathrm{hr}$.

The degree of hydration $\alpha(t)$ (for a spherical particle with an original radius $\mathrm{R}$ ) is given by eqn. (4) $[3,6-8,11]$ where rin is the changing $\mathrm{C} 3 \mathrm{~S}$ radius over time.

$$
\begin{aligned}
& d r_{i n}(t)=K_{1} d t \\
& \alpha(\mathrm{t})=1-\left(\frac{r_{i n}}{R}\right)^{3}
\end{aligned}
$$

The third mechanism is controlled by diffusion, which begins when the radius of the outer C-S-H (rout -rin) reaches a critical value, typically $4 \mu \mathrm{m}$. The rate of hydration is then given by eqn. (5) $[3,6-8,11]$ where rout is the outer $\mathrm{C}-\mathrm{S}-\mathrm{H}$ radius.

$$
d r_{\text {in }}(\mathrm{t})=\frac{K_{2} d t}{r_{\text {out }}-r_{\text {in }}}
$$

As shown in Table 2, the values for K1, K2 and rout - rin are 0.012 $\mu \mathrm{m} / \mathrm{h}, 0.006 \mu \mathrm{m}^{2} / \mathrm{hr}$ and $4 \mu \mathrm{m}$ respectively. The above hydration rates determine the $\mathrm{C}-\mathrm{S}-\mathrm{H}$ growth on the $\mathrm{C} 3 \mathrm{~S}$ particles, either growing inwards (inner C-S-H) our outwards (outer C-S-H). As shown in eqn. (6), for every 1.0 volume units of $\mathrm{C} 3 \mathrm{~S}$ reacting with 1.318 volume units of water, 1.57 volume units of $\mathrm{C}-\mathrm{S}$ - $\mathrm{H}$ and 0.593 volume units of $\mathrm{CH}$ are produced. The model, which can be changed by the user, allocates 1.00 volume units to inner C-S-H (thereby replacing the original volume of C3S at each time-step with inner C-S-H) and 0.57 volume units to outer $\mathrm{C}-\mathrm{S}-\mathrm{H}$. The code is hard-wired to stop the hydration of particles when the rin value reaches zero. This mimics the real hydration of particles, particularly smaller particles. Also, the outer radius of the C-S-H (rout) is fixed when rin reaches zero.

$$
1.0 V_{\mathrm{C} 3 \mathrm{~S}}+1.318 V_{\mathrm{H} 2 \mathrm{O}} \rightarrow 1.57 \mathrm{~V}_{\mathrm{C}-\mathrm{S}-\mathrm{H}}+0.593 V_{\mathrm{CH}}
$$

The $\mathrm{CH}$ is allowed to form in the free pore space. The number of $\mathrm{CH}$ particles generated $(\mathrm{n}(\mathrm{t}))$ is given by eqn. (7) where nmax is the maximum number of $\mathrm{CH}$ particles and assumed to be $20 \%$ of the total number of C3S particles $[3,6-8,11]$ but is changeable by the user. $\alpha$ is another constant which has been reported to be 0.213 but also changeable by the user. The volume of $\mathrm{C} 3 \mathrm{~S}$ converted to $\mathrm{CH}$ as shown in eqn. (5) and the density of $\mathrm{CH}$ are 0.593 and $2.24 \mathrm{~g} / \mathrm{cm} 3$ respectively, and are both adjustable by the user.

$$
n(t)=n_{\max }\left(1-e^{-\alpha t}\right)
$$

Calcium hydroxide typically forms as irregular hexagonal plateshaped crystals in the pore space several microns across. Here, $\mathrm{CH}$ are calculated as spheres with a radius of $\sim 5 \mu \mathrm{m}$ using the volume produced and the number using eqn. (7).

As shown in eqn. (6), the volume of the hydration products is less than the volume of the reactants. This follows Le Chatelierr's [16] 
contraction and leads to chemical shrinkage, which is also calculated by the model as well as the change in water volume, porosity and the heat release during hydration over time.

\section{Simulations and Results}

At each step in the analysis (1 hour here), the growth in C-S-H, reduction of $\mathrm{C} 3 \mathrm{~S}$, production of $\mathrm{CH}$, degree of hydration, heat release during hydration, porosity and chemical shrinkage are calculated.

\section{Processing time}

The model was run for the four cements in Table 1 with a w/c ratio of 0.4 . The pre-processor time required to run a complete analysis for a range of particle distributions is shown in Figure 11 using a Dell Latitude E7270 with an Intel ${ }^{\circ}$ Core $^{\mathrm{m}}$ i5-6300 CPU @ $2.40 \mathrm{GHz}$ (4 CPU's), $2.5 \mathrm{GHz}$. As may be seen, processing time and number of particles are approximately linear. Also, considering the processing time required of $n^{2}$ and $n \cdot \log (n)$ (where $n=$ number of particles) by Navi and Pignat [3,6-8] and Bishnoi [11] respectively, the times are quite short. The use of single precision data in MATLAB significantly reduces the processing time and memory required to run the analysis.

\section{Hydration and microstructure development over time}

Figures $12-15$ shows the $2 \mathrm{D}$ microstructure development at $\mathrm{t}=0,7$, 28 and 91 days $(0,60.3,91.7$ and $99 \%$ hydration) for the four cements. The red, green and dotted black lines circles represent the decreasing $\mathrm{C} 3 \mathrm{~S}$ phase, the outer $\mathrm{C}-\mathrm{S}-\mathrm{H}$ and the original $\mathrm{C} 3 \mathrm{~S}$ radii respectively. As shown, the number of C3S particles left, albeit with significantly reduced in cross-sectional area, demonstrates the models ability to simulate hydration. The increase in $\mathrm{CH}$ for the four cements is shown in Figure 16. As may be seen, there is a rapid increase over the initial 12 hours with a minimal increase thereafter.

Figure 17 shows the changing volume of the C3S particle, total $\mathrm{C}-\mathrm{S}-\mathrm{H}$, water and $\mathrm{CH}$ over the duration of the analysis (100 days or 2,400 hours). Figure 18 shows a zoomed in image of the C3S particles for cement $\mathrm{C} 1$. The figures show the reducing water-filled pore space as hydration continues over time.

Figure 19 presents a phase assemblage diagram for the C3S, C-S-H and $\mathrm{CH}$ over time. As may be seen, the volume $\left(\mathrm{cm}^{3} / 100 \mathrm{~g}\right.$ of cement) of $\mathrm{C} 3 \mathrm{~S}, \mathrm{C}-\mathrm{S}-\mathrm{H}$ and $\mathrm{CH}$ changes over time as expected. The trends shown in Figure 19 are similar to a phase assemblage diagram (Figure 20) by Lothenbach [17]. However, the total volume of C3S is shown to almost disappear which is due to no account taken for the outer CS-H contact/overlapping. Navi and Pignat [3,6-8] considered this issue in their model and used a correction coefficient which used the ratio

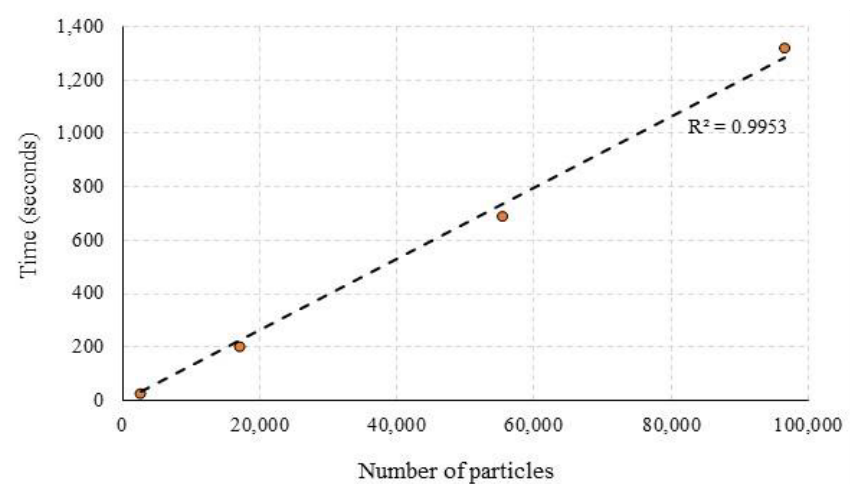

Figure 11: Analysis time for increasing number of particles.
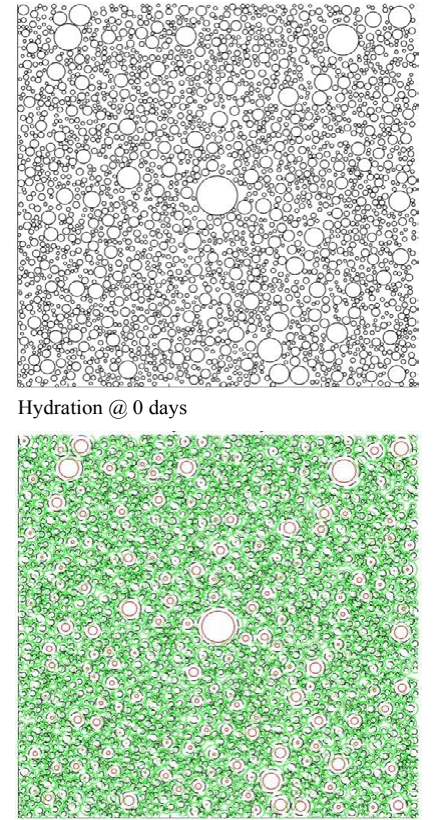

Hydration@28 days
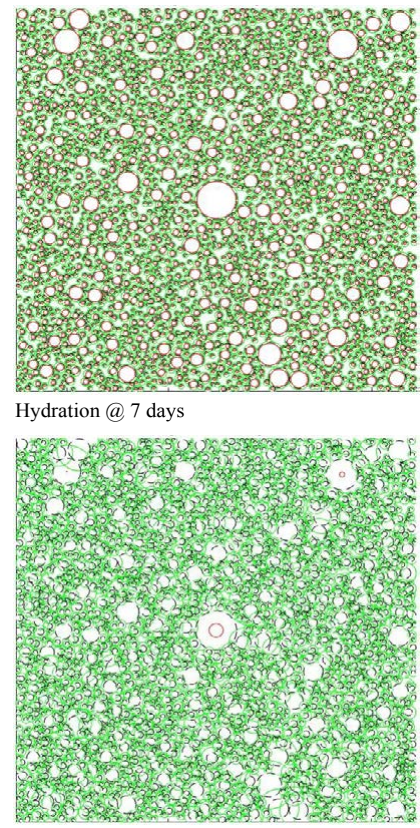

Hydration@91 days

Figure 12: Hydration at $0,7,28$ and 91 days for cement $C_{1}$.

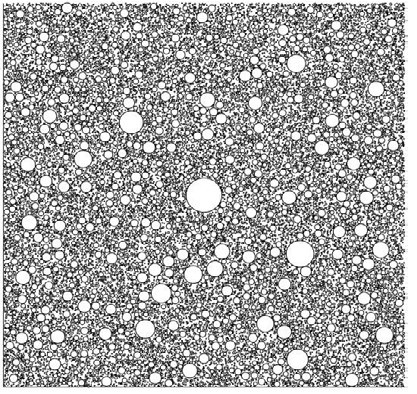

Hydration@ 0 days
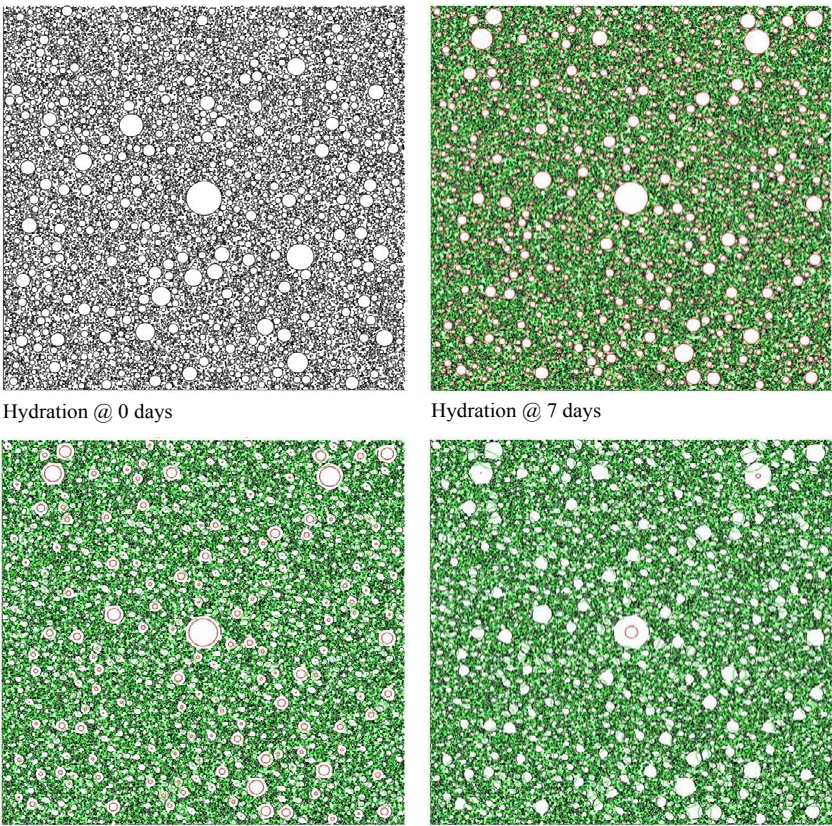

Hydration@28 days

Hydration@ 7 days

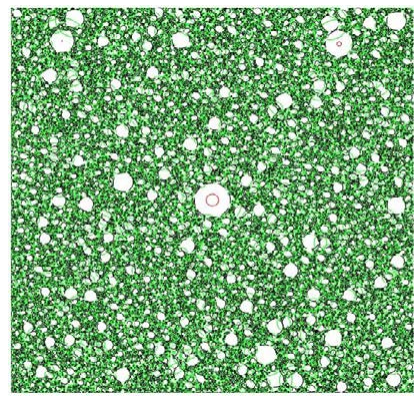

Hydration@91 days

Figure 13: Hydration at $0,7,28$ and 91 days for cement $C_{2}$.

between the particle's free surface to total surface of the particle and the reduction in the available free water in the system. They combined these two restricting effects into eqn. (8) where $v$ is the ratio between the volume of the reaction products and the volume of reactant, $\rho$ is the ratio between the specific mass of the $\mathrm{C} 3 \mathrm{~S}$ and the specific mass of water, and $\omega o$ is the initial $w / c$ ratio $[18,19]$.

$$
d r_{\text {in }}^{i}(t)^{\prime}=d r_{\text {in }}^{i}(t) x\left(\frac{\text { freesurface }}{\text { total surface }}\right)^{i} x\left(1-\frac{v a}{\rho \omega_{o}+\alpha}\right)
$$




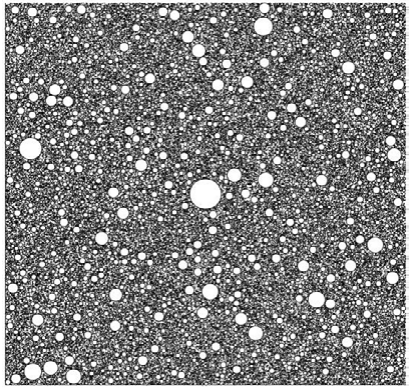

Hydration@ 0 days

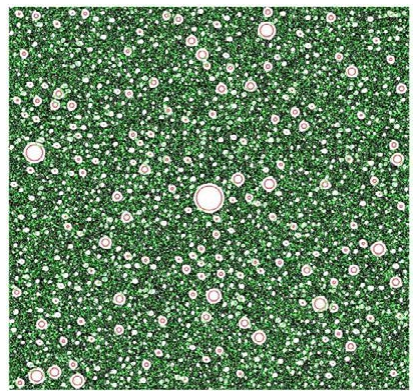

Hydration@28 days

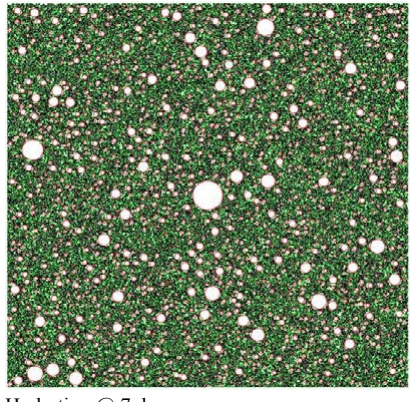

Hydration@7 days

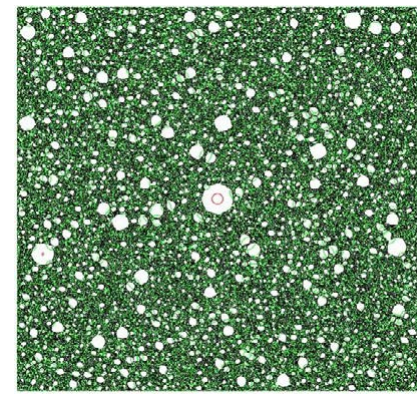

Hydration@91 days

Figure 14: Hydration at $0,7,28$ and 91 days for cement $C_{3}$
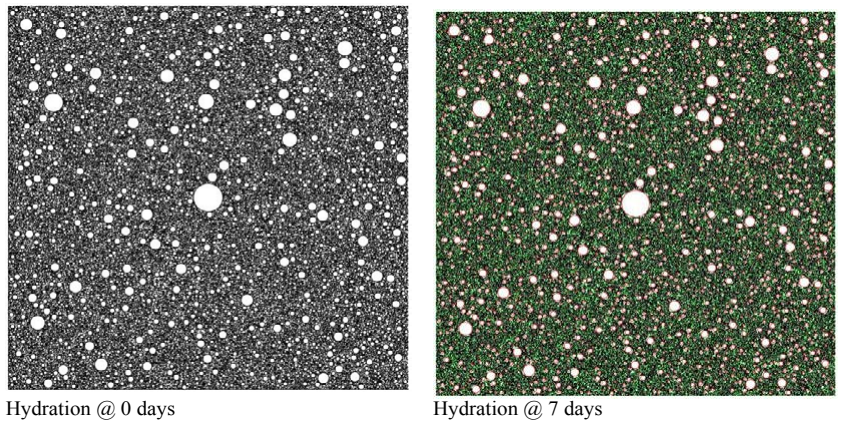

Hydration@ 7 days
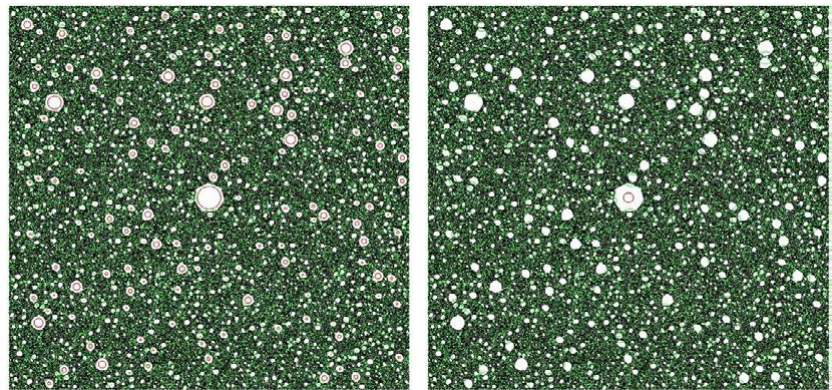

Hydration@28 days

Hydration@91 days

Figure 15: Hydration at $0,7,28$ and 91 days for cement $C_{4}$.

The ideal arrangement can be seen in Figure 21 where the smaller C3S particle are allowed to hydrate first and the larger C3S and subsequent outer C-S-H does not overlap as it makes contact with its smaller neighbours. Expressing this process within the models code is ongoing.

\section{Degree of hydration}

As shown in Figure 22, the degree of hydration reached approximately $100 \%$ (99.8\% exactly) at 100 days. This high hydration may due to the overlapping of the outer C-S-H which does not stunt the growth of outer product. This is further confirmed by only the C3S particles with diameters greater than $13.7 \mu \mathrm{m}$ remaining at 91 days. Similar results and trends were presented by Navi and Pignat for $0.4 \mathrm{w} / \mathrm{c}$ cement paste that shows approximately $81 \%$ hydration at approximately 100 days (Figure 23).

\section{Heat release during hydration}

The calculated heat release during hydration is shown in Figure 24. 


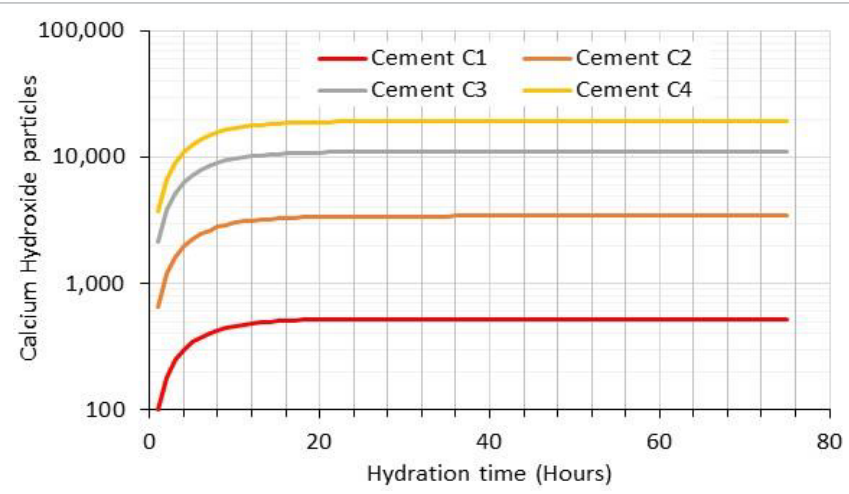

Figure 16: Calcium hydroxide at 2, 4, 12 and 77 hours for cements $C_{1-4}$.

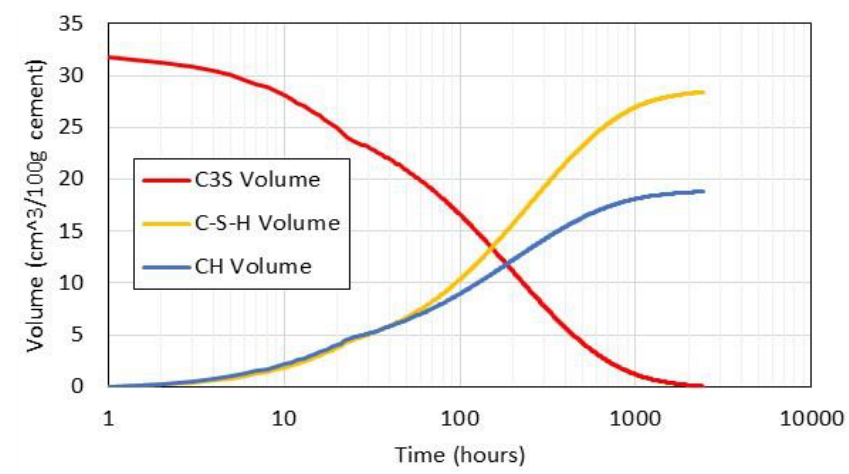

Figure 17: Changing volumes of $\mathrm{C} 3 \mathrm{~S}$, total $\mathrm{C}-\mathrm{S}-\mathrm{H}$, water and $\mathrm{CH}_{\text {cement }} \mathrm{C}_{1}$.

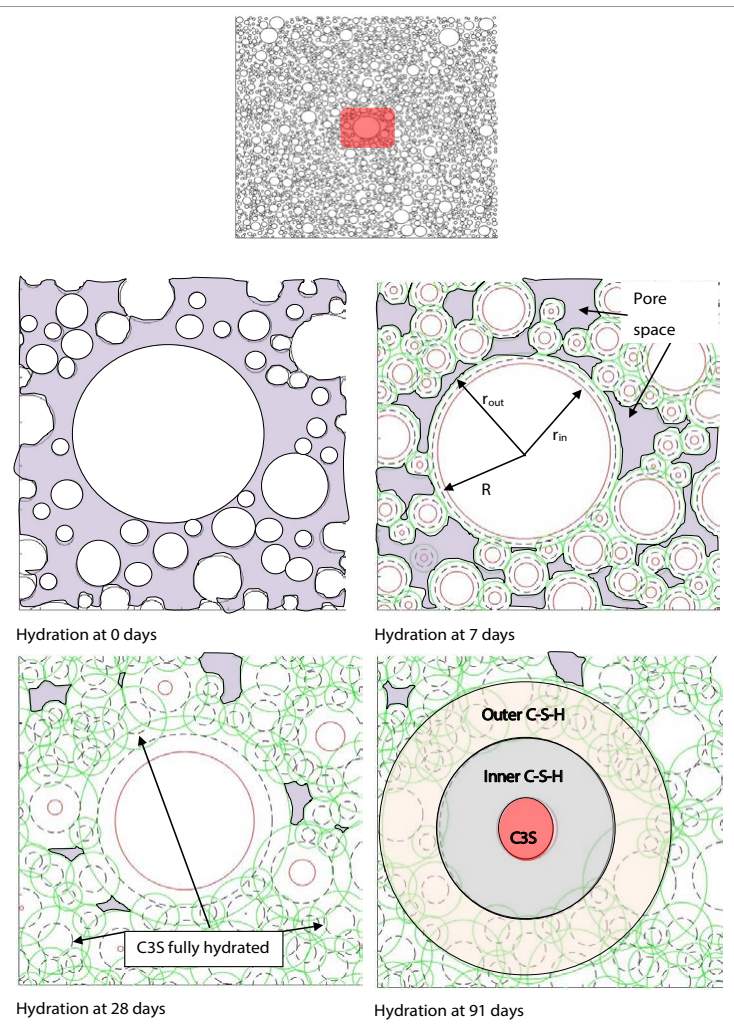

Figure 18: Hydration effects on porosity, dissolution of $\mathrm{C} 3 \mathrm{~S}$ and C-S-H growth over time.

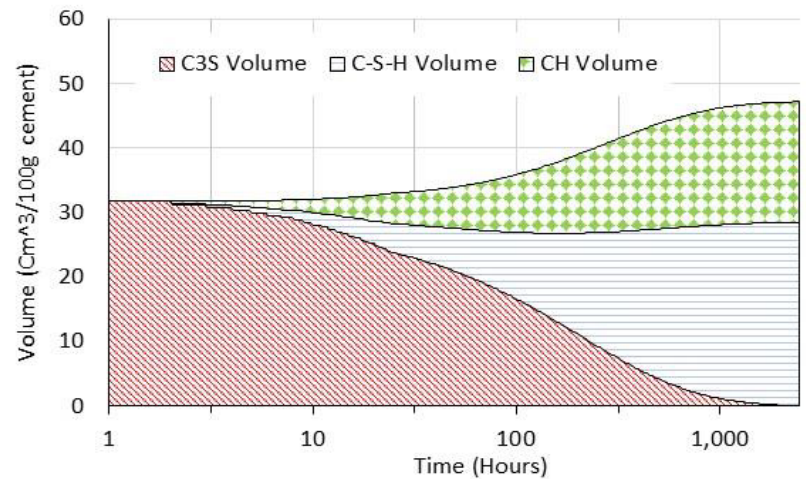

Figure 19: Phase assemblage diagram for $\mathrm{C} 3 \mathrm{~S}, \mathrm{C}-\mathrm{S}-\mathrm{H}$ and $\mathrm{CH}$ over time for cement $\mathrm{C}_{2}$.

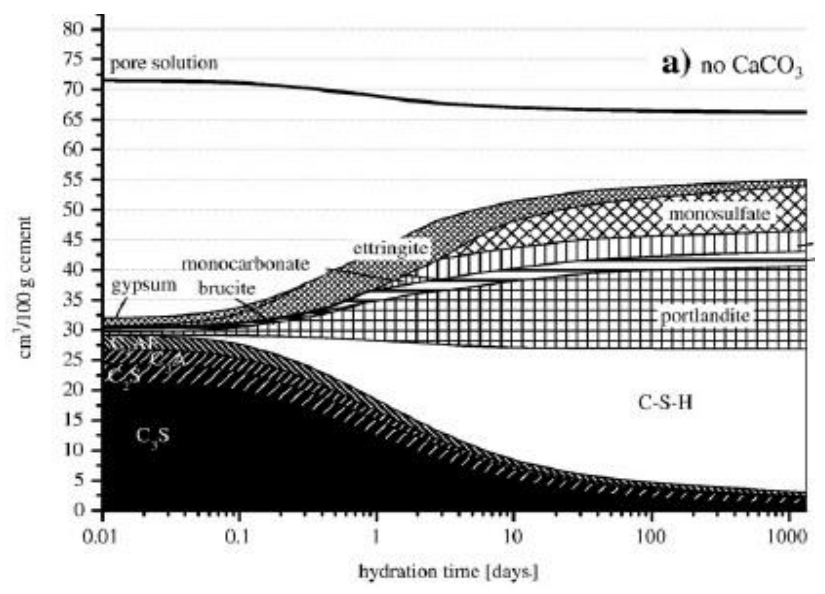

Figure 20: Phase assemblage of a modelled PC hydration of PC [17]
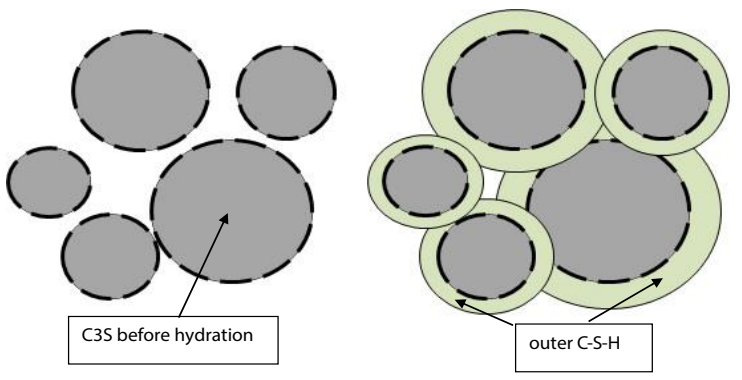

Figure 21: Ideal outer C-S-H contact/intersection arrangement.

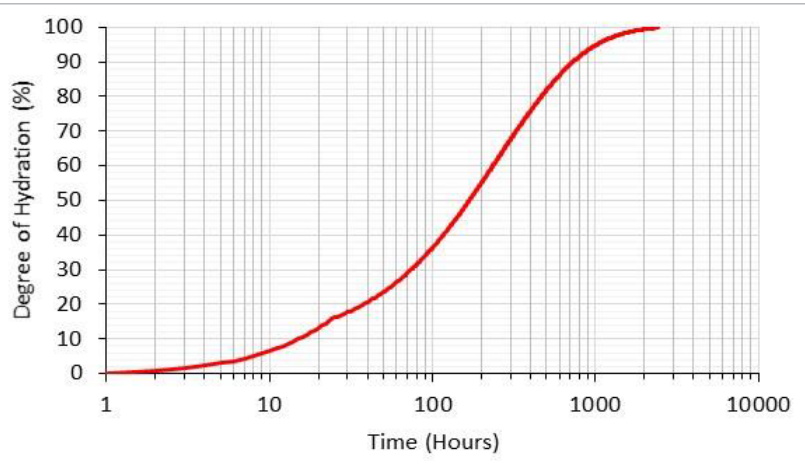

Figure 22: Degree of hydration for cement $C_{1}$. 


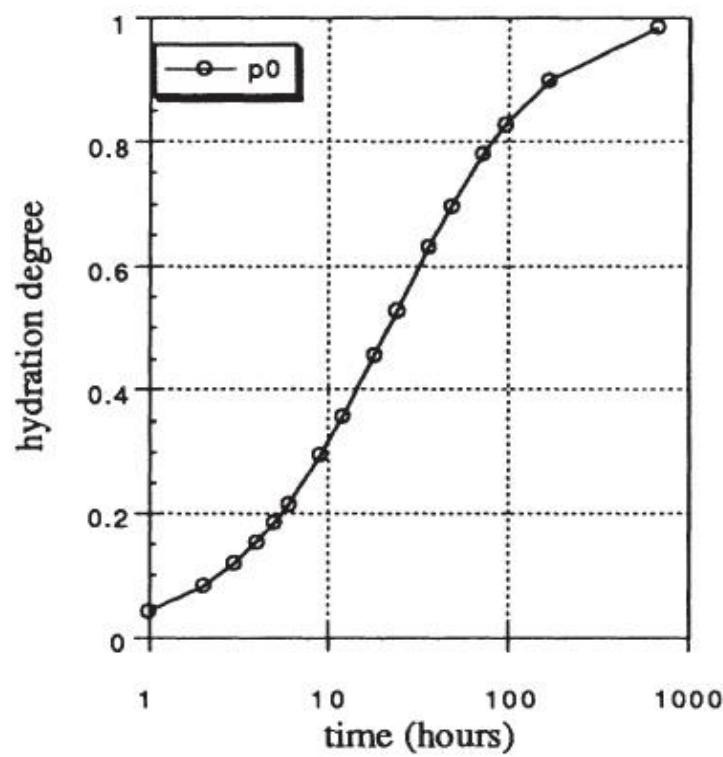

Figure 23: Heat release as calculated by Navi \& Pignat [19] for a 0.4 w/c ratio cement paste.

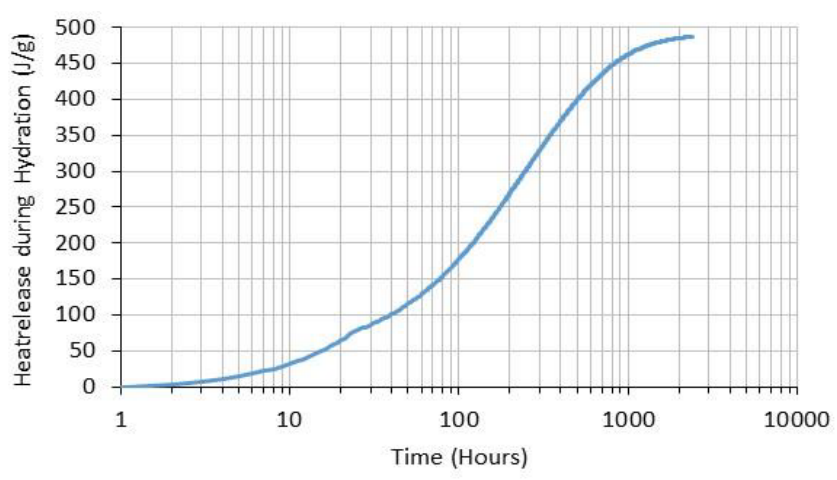

Figure 24: Heat release during hydration.

The calculation in the model is undertaken (at each time step) by determining the mass of reacting $\mathrm{C} 3 \mathrm{~S}$ and multiplying by the enthalpy. The calculated heat release is similar to that both predicted (using CEMHYD3D) and measured for $0.4 \mathrm{w} / \mathrm{c}$ cement over 100 days (Figure 25). As may be seen, the maximum heat release here was $487 \mathrm{~J} / \mathrm{g}$ at 100 days compared to approximately $440 \mathrm{~J} / \mathrm{g}$ in Figure 24.

\section{Chemical shrinkage}

Figure 26 shows the increase in chemical shrinkage as a result of Le Chatelier's contraction [16]. The model determines the chemical shrinkage by diving the sum of $\mathrm{C} 3 \mathrm{~S}$, water, $\mathrm{C}-\mathrm{S}-\mathrm{H}$ and $\mathrm{CH}$ volumes by the total volume and expressing as a percentage. As shown, the maximum shrinkage is approximately $1.6 \%$ at 100 days. Bentz [20,21] reported that the ultimate chemical shrinkage of a typical hydrating Portland cement paste can be approximately $10 \%$ by volume. However, this higher shrinkage is from a cement paste with all phases (C3S, C2A, $\mathrm{C} 3 \mathrm{~A}$ and $\mathrm{C} 4 \mathrm{AF}$ ) included. This is an area where more investigation is required.

\section{Porosity}

The increase in porosity over time is shown in Figure 27 with

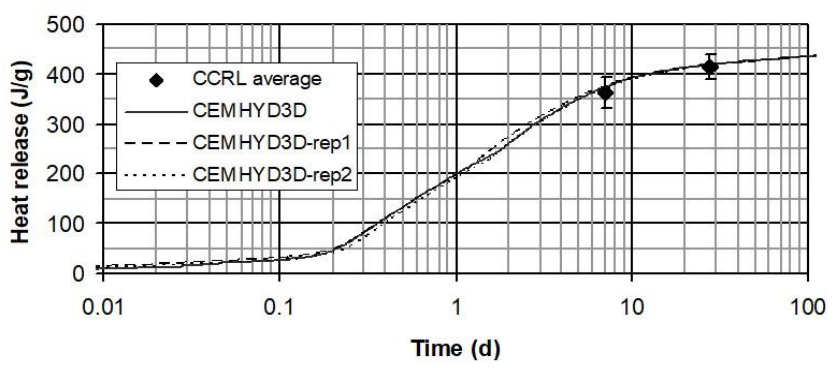

Figure 25: Heat release as calculated by the CEMHYD3D model over 100 days [18].

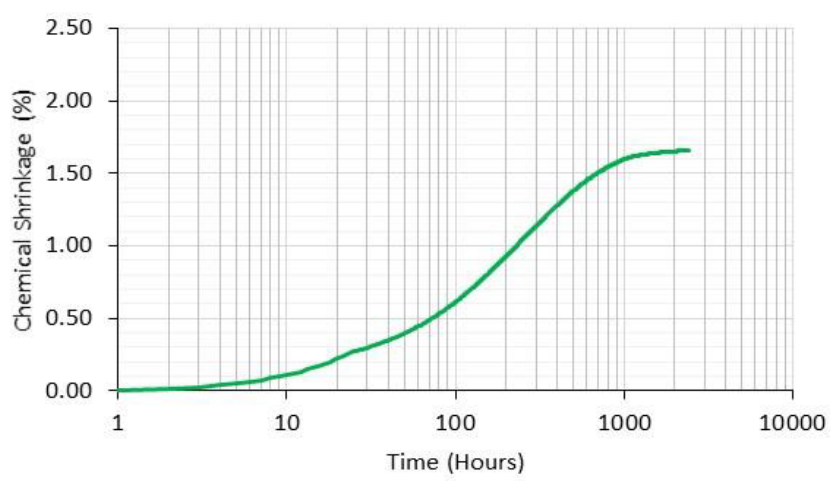

Figure 26: Chemical shrinkage for cement $C_{1}$.

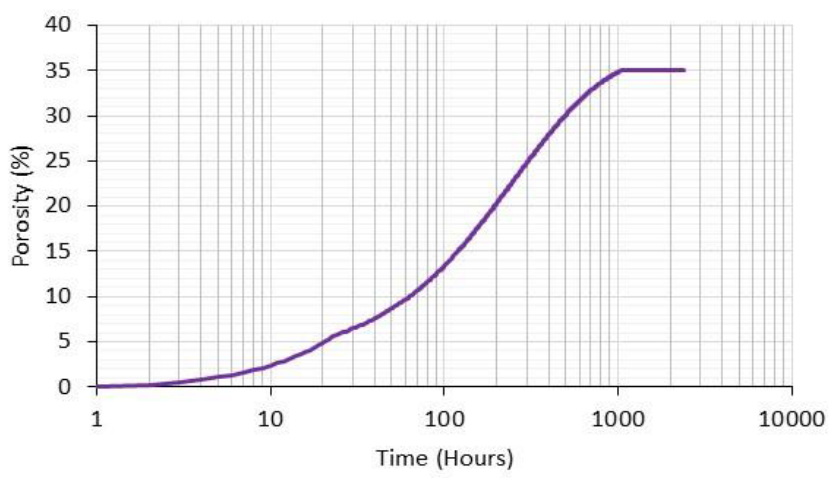

Figure 27: Porosity for cement $C_{1}$.

the maximum $(\sim 35 \%)$ occurring at approximately 1000 hours. Typical porosity in cement pastes following hydration is between $10-20 \%[20,21]$ for a cement paste including all four phases. Future development of the model will include all four phases and it is expected that the porosity observed here will reduce with increasing number of phases undergoing hydration.

\section{Conclusion}

A new model has been developed to simulate cement hydration and microstructure development over time. The model described advances the state of similar vector-based models with some existing computational limitations now overcome. However, while the simulations of several thousand particles in a short period of time above appear reasonable, they have not been calibrated against experimental results or compared with other models in the area. Also, a number of 
practical issues have not yet been addressed in the mathematical model.

For instance, the expanding C-S-H shown crosses-over, which would not be occurring in a real hydrating cement paste. Also, the degree of hydration was shown to go to almost $100 \%$ which, coupled with the cross-over issue above, would not occur, at least not in the time frame here (100 days). The model is also only focused on C3S hydration. These issues are the focus of the ongoing development of the model that will include adding $\mathrm{C} 2 \mathrm{~S}$ and an experimental programme to calibrate the model.

The model has been developed with customisable user input in mind. The model has the potential to be a useful tool for the simulation of cement hydration that can include, in time, supplementary cementitious materials (SCM's) and supplement experimental analysis of new cement products as the industry continues to move towards sustainable cement.

\section{References}

1. Johnson SK, Jennings HM (1986) Computer simulated hydration of a cement model. In proceedings of the 10th CIB congress, International Council for Building Research, Studies, and Documentation, Washington DC, USA, pp: 20860-2095

2. Van Breugel K (1995) Numerical simulation of hydration and microstructural development in hardening cement-based materials:(II) applications. Cem Concr Res 25: 522-530.

3. Navi P, Pignat C (1996) Simulation of cement hydration and the connectivity of the capillary pore space. Adv Cem Based Mater 4: 58-67.

4. Stroeven M, Stroeven P (1999) SPACE system for simulation of aggregated matter application to cement hydration. Cem Concr Res 29: 1299-1304.

5. Jennings HM, Johnson SK (1986) Simulation of microstructure development during the hydration of a cement compound. J Am Ceram Soc 69: 790-795.

6. Navi P, Pignat C (1999) Three-dimensional characterization of the pore structure of a simulated cement paste. Cem Concr Res 29: 507-514

7. Navi P, Pignat C (1999) Effects of cement size distribution on capillary pore structure of the simulated cement paste. Comput Mater Sci 16: 285-293.
8. Pignat C Navi P, Scrivener K (2005) Simulation of cement paste microstructure hydration, pore space characterization and permeability determination. Mater Struct 38: 459-466.

9. Thomas JJ, Biernacki JJ, Bullard JW, Bishnoi S, Dolado JS, et al. (2011) Modeling and simulation of cement hydration kinetics and microstructure development. Cem Concr Res 41: 1257-1278.

10. Bullard JW (2007) A three-dimensional microstructural model of reactions and transport in aqueous mineral systems. Modell Simul Mater Sci Eng 15: 711 738

11. Bishnoi S, Scrivener KL (2009) $\mu$ ic: a new platform for modelling the hydration of cements. Cem Concr Res 39: 266-274.

12. Bentz DP (1997) Three-dimensional computer simulation of cement hydration and microstructure development. J Am Ceram Soc 80: 3-21.

13. Kondo R, Ueda S (1968) Kinetics of hydration of cements, Proceedings of the 5 th international symposium on chemistry of cement. Tokyo, pp: 203-248.

14. Gartner EM (1997) A proposed mechanism for the growth of C-S-H during the hydration of tricalcium silicate. Cem Concr Res 27: 665-672.

15. Juilland P, Gallucci E, Flatt R, Scrivener K (2010) Dissolution theory applied to the induction period in alite hydration. Cem Concr Res 40: 831-844.

16. Steinour HH (1961) Progress in the chemistry of cement, I887-1960, Bull 130 Res Lab of Portland Cement Association, Skokie, IL, US, (reprinted from) J PCA Res Dev Lab 3: 2-11.

17. Lothenbach B, Le Saout G, Gallucci E, Scrivener K (2008) Influence of limestone on the hydration of Portland cements. Cem Concr Res 38: 848-860.

18. Bentz DP (2006) Modeling the influence of limestone filler on cement hydration using CEMHYD3D. Cem Concr Compos 28: 124-129.

19. Navi P, Pignat C (1996) Simulation of effects of small inert grains on cement hydration and its contact surfaces. In the Modelling of Microstructure and Its Potential for Studying Transport, Properties and Durability, pp: 227-240.

20. Bentz DP (2008) A review of early-age properties of cement-based materials. Cem Concr Res 38: 196-204.

21. Bentz DP, Garboczi EJ (1991) A digitized simulation model for microstructural development. Ceram Trans 16: 211-226. 